\title{
Evaluando la participación institucional: la "tem- peratura” de la deliberación y sus consecuencias
}

\author{
Marc PARÉS \\ Universitat Autònoma de Barcelona \\ marc.pares@uab.cat \\ Hug MARCH \\ Universitat Oberta de Catalunya \\ hmarch@uoc.edu
}

Recibido: 14-05-2013

Aceptado: 18-04-2014

\begin{abstract}
Resumen:
Los cambios experimentados recientemente en las sociedades contemporáneas están transformando las formas de participación de la ciudadanía en la esfera pública, poniendo en tela de juicio las iniciativas de participación institucional promovidas por diversas administraciones durante la última década. Resulta del todo necesario evaluar estas iniciativas si se quiere garantizar su funcionalidad en este nuevo escenario. En este contexto, el presente artículo propone distintos criterios e instrumentos de evaluación de la participación y los aplica a una experiencia concreta: el proceso participativo sobre la gestión forestal en la Muntanya de Sant Miquel, en Setcases (Cataluña). Al mismo tiempo, el artículo se pregunta sobre cuáles son las mejores formas y condiciones para promover una participación efectiva, incidiendo en el debate sobre la "temperatura" de la deliberación. Concluimos que es extremadamente difícil combinar las lógicas de deliberación fría y caliente. Sin embargo, esta puede ser la solución más adecuada cuando el tema a abordar despierte un alto conflicto de intereses entre actores organizados y, al mismo tiempo, requiera ser abordado desde la lógica del interés colectivo porque afecta al conjunto de una comunidad.
\end{abstract}

Palabras clave: participación ciudadana, evaluación, gestión participada, deliberación, temperatura de la deliberación 


\title{
Assessing institutional participation: the 'temperature' of deliberation and its consequences
}

\begin{abstract}
Changes recently occurred in contemporary societies are transforming the forms of citizens' participation in the public sphere, challenging institutional participation initiatives promoted by various governments over the past decade. It is quite necessary to evaluate these initiatives to ensure its functionality in this new scenario. In this context, this article proposes different criteria and participation assessment instruments in order to apply them into a concrete experience: the participatory process on forest management carried out in Muntanya de Sant Miquel in Setcases (Cataluña). At the same time, the article reflects on what are the best ways and conditions to promote effective participation, focusing its attention on the debate on the 'temperature' of deliberation. We conclude that it is extremely difficult to combine hot and cold deliberation. However, this may be the best solution when the participatory topic addresses high conflict of interests between stakeholders and, at the same time, requires to be addressed from the logic of collective interest because it affects the whole community.
\end{abstract}

Key words:citizen participation, evaluation, participatory management, deliberation, deliberation temperature

\section{Referencia normalizada}

Parès, M., March, H. (2014). "Evaluando la participación institucional: la "temperatura” de la deliberación y sus consecuencias”. Política y Sociedad, Vol 51, Núm. 2: 565-594

Sumario: Introducción. 1.El método de evaluación: una propuesta de criterios y herramientas. 2.La Muntanya de Sant Miquel: un ejemplo paradigmático de la participación en la gestión forestal. 3.Los resultados de la evaluación. 4.Conclusiones finales.

\section{Introducción}

Son numerosas las administraciones públicas españolas, sobretodo locales, que durante los últimos años han experimentado con procesos participativos (Subirats et al., 2001; Del Pino y Colina, 2003; Alguacil, 2006; Font y Galais, 2009; Parés, 2009). Seguramente son muchos y diversos los objetivos que se han perseguido con este tipos de experiencias. Como apunta Ruano de la Fuente (2010), frecuentemente estos objetivos son ambiguos y genéricos, siendo muchas de estas experiencias incapaces de dar respuesta a los problemas de opacidad y a los déficits democráticos de las administraciones públicas españolas. Podemos destacar por lo menos dos grandes objetivos que suelen prevaler por encima los demás (Font, 2001; Blanco et al., 2011). En primer lugar tendríamos aquellas experiencias de participación ciudadana que se han impulsado con la intención de mejorar las políticas públicas. Se entiende bajo este argumento que el hecho de involucrar en el proceso de elaboración de las políticas públicas a los actores clave de un problema, a los colectivos 
que se benefician de la política en cuestión (o que son perjudicados por la misma) y/o a la ciudadanía en general, permitirá un mejor diagnóstico del problema y, al mismo tiempo, facilitará la aparición de soluciones creativas e innovadoras que pueden mejorar la respuesta de la administración frente al problema que se pretende resolver. En segundo lugar, encontramos aquellos casos en los que se argumenta que hacer participar a la ciudadanía en los procesos de toma de decisión pública puede promover -entre los participantes- una mayor comprensión del problema y una corresponsabilización de la solución, con lo que la política pública finalmente implementada obtendrá un mayor grado de legitimidad.

Durante los años precedentes a la actual crisis vimos incrementar las experiencias de participación ciudadana promovidas por las administraciones, no sólo locales sino también autonómicas ${ }^{1}$. Sin embargo, más recientemente diversos autores han puesto en tela de juicio la calidad de estas experiencias y su efectiva capacidad para lograr estos dos grandes objetivos (Ruano de la Fuente, 2010; Parés, 2009; Blanco et al., 2011). Este es un primer motivo que justificaría la necesidad de disponer de instrumentos de evaluación que nos permitan identificar las fortalezas y las debilidades de las experiencias participativas y/o discernir las experiencias participativas de calidad de aquellas que no los son. En esta lógica se enmarca, entre otros, el trabajo realizado por Castellà y Jorba (2005) evaluando las experiencias locales de participación en Cataluña.

La situación actual, sin embargo, es un poco más compleja y requiere profundizar en estos instrumentos de evaluación. Los cambios que están sufriendo las sociedades contemporáneas en los últimos años están transformando también las formas de participación de la ciudadanía en la esfera pública (Subirats, 2011). Estos cambios, originados por la situación de crisis económico-financiera pero también por muchos otros factores (la revolución tecnológica de Internet, nuevos modelos de relación social, laboral y familiar, nuevos elementos de complejidad social, etc.), obligan a replantearnos tanto la necesidad como la forma cómo se están llevando a cabo las experiencias de participación ciudadana institucional. Una primera evidencia la encontramos en la propia administración: muchas de las administraciones que habían liderado este tipo de experiencias han dejado de promoverlas y/o han reducido su intensidad (Díaz, 2012), ya sea como consecuencia de los recortes en la administración o por un cambio de sus prioridades (en muchas ocasiones vinculado a un cambio de gobierno) ${ }^{2}$. Otra evidencia la hallamos en la sociedad civil: cada vez son más los ejemplos de iniciativas ciudadanas que, ya sea desde el "no nos repre-

${ }^{1}$ Hemos identificado experiencias de participación ciudadana promovidas por la administración autonómica en Aragón, Comunidad Valenciana, País Vasco, Islas Canarias y Cataluña.

${ }^{2}$ Algunos ejemplos los podemos encontrar en los municipios que impulsaban los presupuestos participativos en el marco de la Red Estatal por los Presupuestos Participativos o en distintos gobiernos autonómicos como el de Cataluña o el de Aragón. 
sentan” del movimiento 15M o desde la percepción que la administración no está siendo capaz de resolver sus problemas cotidianos, optan por nuevas formas de auto-organización basadas en la cooperación y la colaboración entre ciudadanos/as, muchas veces al margen del Estado.

En este contexto, la evaluación de las experiencias participativas llevadas a cabo por la administración resulta todavía más relevante, pues no sólo se trata de mejorar la calidad de estas experiencias sino que, sobretodo, se trata de garantizar que éstas sean útiles y funcionales en la sociedad actual. En otras palabras, en un momento en el que crece la desconfianza de la sociedad hacia la clase política ${ }^{3}$ y los ciudadanos están optando cada vez más por auto-organizarse mediante nuevas formas de participación-cooperación al margen del Estado, las administraciones deben pensárselo muy bien antes de iniciar un proceso participativo. En un marco de restricción económica -que obliga a priorizar los procesos participativos que se quieren impulsar- sólo tiene sentido que las administraciones abran procesos participativos si pueden garantizar, primero, que no frustraran las expectativas de los participantes, y segundo, que los resultados se traducirán en políticas eficaces que serán capaces de producir mejoras efectivas en la calidad de vida de sus conciudadanos. En este escenario, además, el diseño, la difusión, la comunicación y la credibilidad del proceso participativo van a jugar un papel clave para conseguir la implicación de una ciudadanía que tiende a desconfiar de quien lo promueve. Por todo ello, disponer de instrumentos para evaluar la participación resulta crucial para aprender de las experiencias evaluadas y poder mejorar las experiencias futuras, adaptando las formas institucionales de participación ciudadana al nuevo escenario que se está dibujando en la sociedad actual.

Con el objetivo de contribuir a estos debates y ofrecer herramientas de aplicabilidad, el presente artículo propone distintos criterios e instrumentos de evaluación de la participación y los aplica a una experiencia concreta: el proceso participativo sobre la gestión forestal en la Muntanya de Sant Miquel, en Setcases (Cataluña). Como se verá, la evaluación de esta experiencia servirá para ejemplificar la aplicación de los instrumentos que aquí se proponen, ayudará a identificar elementos de mejora útiles para otras experiencias y, al mismo tiempo, nos permitirá aportar diversas reflexiones alrededor de las condiciones en las que abordar un proceso participativo. Más concretamente, nos permitirá profundizar en las consecuencias de la "temperatura" de la deliberación.

El artículo consta de cinco apartados. En el primer apartado se revisa la literatura reciente sobre evaluación de la participación y se introduce el debate sobre la temperatura de la deliberación. En la segunda sección del artículo se desarrolla la propuesta metodológica, con los criterios y las herramientas que utilizaremos para

\footnotetext{
${ }^{3}$ Desde febrero de 2010 los barómetros mensuales del CIS muestran que los ciudadanos consideran que "la clase política y los partidos” son el tercer problema de España, detrás del paro y los problemas de índole económica
} 
evaluar la experiencia que aquí presentamos. A continuación se presenta el estudio de caso que hemos escogido para evaluar. En el cuarto apartado muestran los resultados de la evaluación y, finalmente, el artículo concluye apuntando algunas propuestas de mejora y realizando algunas reflexiones sobre las consecuencias de la participación en función de la "temperatura" de la deliberación.

\section{La evaluación de la participación y la temperatura de la deliberación}

En los últimos años ha emergido en la Ciencia Política y de la Administración un intenso debate sobre cómo evaluar la participación de la ciudadanía en las instituciones públicas. Diversas de las contribuciones a este debate focalizan su atención en la evaluación de los espacios y mecanismos concretos de participación: procesos participativos, órganos de participación, mecanismos diversos como talleres, jurados ciudadanos o encuestas deliberativas, etc. (Anduiza y De Maya, 2005; Castellà y Jorba, 2005; Jorba et al., 2007; Papadopoulus y Warin, 2007; Cuesta et al., 2008; Parés y Castellà, 2009; Parés y Resende, 2009; Blanco y Ballester, 2011). La mayoría de las investigaciones llevadas a cabo con esta finalidad han comprendido la evaluación o bien como un "juicio", entendiendo que la evaluación debe determinar en qué medida el proceso (y sus resultados) se acerca a un modelo ideal, o bien como una "negociación”, en la que los propios participantes definen en qué debe consistir el éxito del proceso (ver Alvira, 1996; Tamayo, 2004; Jorba et al., 2007). Ambos enfoques requieren concretar unos criterios que definan la participación "ideal” para poder contrastar en qué medida la experiencia evaluada cumple o no con dichos criterios. En el presente artículo revisamos algunos de estos criterios y realizamos una nueva propuesta acorde con las características del momento actual.

Podemos distinguir tres grandes aproximaciones a la evaluación de prácticas participativas: las que se centran en los procedimientos, las que se fijan en las consecuencias de la participación y las que integran ambas perspectivas. Gran parte de los estudios recientes han puesto su atención en las cuestiones procedimentales de la participación, como la inclusión de todas las voces, el respeto mutuo entre los participantes, la economía del desacuerdo moral o las posibilidades de modificación de las posiciones iniciales (Bobbio, 2010; Hendriks, 2006; Jorba, 2008; Sunstein y Hastie, 2008). Menos estudios, sin embargo, han explorado los resultados de la participación (Schkade et al., 2006; Hendriks et al., 2007). Así, tal y como observan Blanco et al. (2011), a pesar del claro crecimiento de las iniciativas de participación hay una cierta debilidad en lo relativo a las evidencias de los efectos de la participación.

Por otro lado, y más allá de los efectos que podría tener la participación, diversos estudios han examinado los factores que pueden mejorar o empeorar los resultados de la participación. En este sentido, algunos autores han destacado la importancia de la calidad participativa (procedimental) como un hecho que determina los resultados de la misma (Papadopoulus y Warin, 2007; Parés, 2009). En esta línea, Fung (2003) describe ocho modelos de diseño institucional de la participación y 
analiza sus consecuencias. Con una lógica similar y basándose en diferentes aportaciones teóricas, Blanco y Ballester (2011) identifican cinco condiciones que mejoran el potencial transformador de la participación, son las siguientes: un liderazgo político fuerte tanto del proceso participativo como de las políticas afectadas (Haus et al., 2005), un enfoque integral de la política pública sometida a participación (Wagenaar, 2007), una amplia visibilidad del proceso participativo llevado a cabo (Font y Blanco, 2006), una alta capacidad de impacto de la ciudadanía a través del proceso (Arnstein, 1969; Fung, 2006) y un verdadero cambio cultural de políticos, técnicos y ciudadanos (Brugué, 2004; Subirats, 2003).

Una de las principales contribuciones a la evaluación de la participación es la realizada por los teóricos de la deliberación (Ackerman y Fishkin, 2004; Dryzek, 2002; Fishkin, 1991, 1995, 2009; Fishkin y Laslett, 2003). La deliberación, y las condiciones en que esta se produce, es uno de los principales ejes de análisis del presente artículo. A nuestro juicio, en una sociedad cada vez más politizada, pero también más compleja, la forma cómo se produce el intercambio de argumentos en los procesos participativos es un elemento crucial. Es bien conocido que la deliberación no sólo contribuye a mostrar las distintas posiciones presentes en los problemas complejos sino que también permite que estas opiniones evolucionen, cambien y se modulen a medida que se va incorporando nueva información y se van intercambiando los argumentos (Cuesta et al. 2008; Fishkin, 2009: Jorba, 2008). Además, tal y como apuntan Cuesta et al. (2008), la deliberación es viable. Cuando se construyen propuestas acotadas y eficaces para escuchar a la ciudadanía, ésta está dispuesta a invertir su tiempo en el debate de las cuestiones colectivas. Profundizaremos en ello en las siguientes secciones.

Desde la óptica de los criterios de calidad en la deliberación, destacan las aportaciones de Gutmann y Thompson (1996, 2004). Estos autores entienden que un espacio deliberativo de calidad será aquél en el que estén representadas todas las voces, se intercambian razones y argumentos, se ofrezca información de forma accesible y comprensible, se minimicen los desacuerdos morales y se vincule la participación a una decisión concreta. En una línea similar Fox y Miller (1995) argumentan que el buen funcionamiento deliberativo será aquél que sea capaz de organizar un diálogo constructivo y democrático, evitando tanto el monólogo como la dispersión. Siguiendo este argumento, Brugué (2009) sostiene que para articular un diálogo de estas características, desde el punto de vista más operativo, el promotor de la participación debería garantizar tres tareas imprescindibles: a) explicarse, clarificando y comunicando los contenidos y los objetivos del debate, b) escuchar a la ciudadanía, invitándola a espacios de debate donde expresarse de manera clara y ordenada, y c) responder, dando cuenta de las aportaciones recibidas y de cómo éstas se han trasladado a una decisión concreta.

Partiendo de todas estas visiones más generales sobre cómo debería ser un proceso participativo de "calidad", encontramos algunas propuestas más aplicadas que, con el objetivo de ofrecer herramientas para la evaluación de las experiencias participativas, integran criterios de calidad participativa (sobretodo procedimentales pero también sustantivos) con metodologías de análisis. En este sentido cabe desta- 
car la propuesta de indicadores de Anduiza y De Maya (2005), la propuesta metodológica de Jorba et al. (2007) y la propuesta de criterios y técnicas de evaluación de Parés y Castellà (2009).

En síntesis, pues, vemos cómo en los últimos años se han realizado, desde distintas aproximaciones teóricas, diversas propuestas tanto sustantivas como metodológicas para evaluar las experiencias de participación ciudadana. Ahora bien, ¿cuáles de estas propuestas de evaluación deberíamos aplicar en el actual contexto de crisis económica y de desconfianza de la ciudadanía hacia los poderes públicos? En la siguiente sección del artículo, basándonos en algunas de las aportaciones citadas anteriormente, realizamos una nueva propuesta con el objetivo de dar respuesta a esta pregunta. Tal y como argumentaremos más adelante, entendemos que la propuesta evaluativa que aquí se realiza (y se pone en práctica) puede ser de gran utilidad para evaluar la participación en el momento actual.

Resulta evidente que no todos los procesos participativos son iguales ni se desarrollan bajo las mismas condiciones. Las características del contexto, los participantes, el diseño, la lógica deliberativa e incluso los objetivos pueden ser bien distintos. Mansbridge et al. (2010), por ejemplo, definen cuatro formas distintas de entender y aplicar la deliberación. Bobbio y Pomatto (2007), centrándose exclusivamente en las formas institucionales de implicación de la ciudadanía en la esfera pública, distinguen entre las formas de presión y las formas de confrontación. Las primeras se basarían en la presión del pueblo, supuestamente homogéneo, frente a la administración. Generalmente éstas son formas más extensas e inclusivas de participación, suelen utilizar metodologías de interacción por agregación y pretenden tener un carácter más decisivo y vinculante. Las segundas, más centradas en la deliberación, partirían de la base de una sociedad pluralista y entenderían la participación como una confrontación dialogada entre ciudadanos que tienen ideas o intereses contrapuestos; con la finalidad de encontrar puntos en común. En este caso, se busca la participación de todos los puntos de vista, seleccionando los actores que deben estar presentes y se pone el acento en el procedimiento, utilizando metodologías de interacción basadas en el diálogo y no en la agregación.

En este contexto, Fung (2003) distingue entre la deliberación "caliente” y la deliberación "fría". La primera se refiere a aquellos casos en los que los participantes tienen un interés fuerte en el tema sometido a deliberación; mientras que la segunda hace referencia a aquellos casos en los que los participantes no tienen un interés preestablecido, con lo que van a la deliberación con la mente más abierta y sin posiciones prefijadas, pero también con menos pasión. Para Fung (2003) es preferible una deliberación caliente, pues resulta más atractiva para los participantes, estos van a dedicar más esfuerzos y van a producir soluciones más creativas; es más probable que perdure en el tiempo y los resultados tienen más posibilidades de ser legitimados e implementados. Bobbio y Pomatto (2007), por otro lado, relacionan la deliberación caliente con las formas de presión y la deliberación fría con las formas de confrontación. Bobbio (2010), además, argumenta que la posición inicial de los participantes en una deliberación condiciona tanto la temperatura de la deliberación como su efectividad. El autor identifica tres dimensiones que definen las posiciones 
iniciales de los participantes: el nivel de definición de sus posiciones, el nivel de conocimiento en el que éstas se fundamentan, y el nivel de libertad de los participantes para cambiar su posición (tabla 1). Cuando las posiciones están bien definidas y se fundamentan en un alto nivel de conocimiento, entonces la temperatura de la deliberación va a ser caliente, mientras que en el escenario opuesto tendremos las condiciones para una deliberación fría. Por último, algunos autores defienden que la deliberación puede funcionar bien en condiciones frías, de poca conflictividad (Held, 1995); pero fracasa en situaciones calientes. Sin embargo, Brugué y Parés (2012) a partir de un estudio de caso concluyen que una deliberación de calidad también es viable y funcional en contextos "calientes", siempre y cuando se sigan unas determinadas pautas de gestión de la misma.

Tabla 1: Posiciones iniciales en la deliberación

\begin{tabular}{|c|c|c|}
\hline & $\begin{array}{c}\text { Nivel de definición de } \\
\text { posiciones } \\
\text {-ALTO- }\end{array}$ & $\begin{array}{c}\text { Nivel de definición de } \\
\text { posiciones } \\
\text {-BAJO- }\end{array}$ \\
\hline $\begin{array}{c}\text { Nivel de conocimiento - } \\
\text { ALTO- }\end{array}$ & Certeza en el juicio & Juicio en suspensión \\
\hline $\begin{array}{c}\text { Nivel de conocimiento - } \\
\text { BAJO- }\end{array}$ & Prejuicio & Incertidumbre en el juicio \\
\hline
\end{tabular}

Fuente: elaboración propia a partir de Bobbio (2010)

Hasta donde nosotros conocemos existen pocos datos empíricos sobre los méritos y las circunstancias más apropiadas en las que pueden ser más viables y más funcionales las formas de deliberación caliente o las formas de deliberación fría. Brugué y Parés (2012) llenan parte de este vacío analizando el caso de la Mesa de la Montaña en Aragón, una experiencia de deliberación “caliente”.

Entendemos que este debate es de gran relevancia en el momento actual. Cada vez es más frecuente que la participación se lleve a cabo en contextos "calientes" en los que los participantes tienen intereses fuertes y posiciones preestablecidas. Al mismo tiempo, sin embargo, cada vez hay más ciudadanía politizada y van multiplicándose las reivindicaciones de nuevos espacios participativos amplios e inclusivos, dirigidos al conjunto de la sociedad y capaces de presionar a los gobiernos. Es decir, espacios de lógica agregativa y/o de deliberación "fría”. La combinación de actores, lógicas y momentos de distinta temperatura deliberativa es un fenómeno que, dadas las características de la nueva sociedad emergente (Subirats y Parés, 2014), puede ser cada vez más frecuente. En la presente investigación contribuiremos a este debate aportando un análisis en profundidad de una experiencia que, como veremos, comparte al mismo tiempo elementos de deliberación "fría" y elementos de deliberación "caliente”. 


\section{El método de evaluación: una propuesta de criterios y herramientas}

En el apartado precedente hemos argumentado que la complejidad tanto de la sociedad actual como de sus problemas nos conducen a pensar que la calidad de la deliberación, el contexto y la forma cómo esta se produce deben convertirse en un elemento clave en cualquier proceso participativo y, en consecuencia, deben ser un eje central de su evaluación. Al mismo tiempo, sin embargo, hay otro elemento vinculado al contexto histórico que estamos atravesando que entendemos que debe guiar nuestro enfoque evaluativo. Se trata de la desconfianza de la ciudadanía en la clase política, que conduce a un creciente escepticismo hacia los procesos participativos promovidos por las instituciones públicas. Frente a esta realidad entendemos que es necesario que la evaluación de los procesos participativos se focalice, también, en los resultados de los mismos. Es a través de unos resultados tangibles y eficaces que este tipo de iniciativas institucionales pueden ganar credibilidad.

A partir de estas dos premisas presentamos a continuación una propuesta evaluativa que, basándose en la literatura sobre la materia, se adapta a las características del actual contexto de crisis económica, política y social. Como ya hemos comentado anteriormente el objetivo de esta contribución es proponer una metodología evaluativa y ponerla en práctica evaluando un proceso participativo concreto desarrollado en el actual contexto de crisis. La finalidad última de esta evaluación es identificar aquellos puntos más relevantes de la experiencia analizada que puedan ser exportados a otros procesos de carácter similar y, a su vez, dar pistas y herramientas para la mejora continua de tales procesos en el escenario actual.

Partiendo de las propuestas metodológicas de evaluación de Jorba et al. (2007), Jorba y Anduiza (2009) y Parés y Castellà (2009), proponemos realizar la evaluación del presente estudio de caso utilizando una batería de criterios y preguntas de evaluación estructurados en base a cinco grandes ámbitos: la coordinación del proceso, la tipología de participantes, la temática sobre la que se participación, el método utilizado y las consecuencias de la participación. Se trata, por lo tanto, de un enfoque integral que pretende analizar tanto los factores procedimentales como los efectos de la participación.

Para cada ámbito se han seleccionado distintos criterios que se ajustan tanto a las características del caso que queremos evaluar cómo a los objetivos de la evaluación y a las características del momento actual. Se ha procurado que los criterios sean simples, específicos y se han consensuado con la Direcció General de Participació Ciutadana, que era quien promovía el proceso. Veamos con un poco más de detalle los criterios seleccionados para la evaluación del estudio de caso.

En relación a la coordinación del proceso entendemos que en un momento en el que la ciudadanía pone en duda tanto la legitimidad como la funcionalidad de los poderes públicos, es necesario que las iniciativas de participación institucional se desarrollen bajo un amplio consenso sobre la necesidad y el método llevado a cabo y, tal y como apuntan Haus et al. (2005), se desarrollen bajo un liderazgo político claro y comprometido con los resultados. En este sentido, la claridad de los objetivos que defienden Parés y Castellà (2009) nos parece crucial. Al mismo tiempo, 
aunque el contexto de crisis económica invite a recortar los recursos dedicados a la participación, es importante tener en cuenta que tanto si queremos apostar por procesos participativos amplios como si perseguimos una deliberación de calidad, determinados recursos serán del todo necesarios.

El debate sobre quiénes participan es otro elemento importante a tener en cuenta en cualquier evaluación. Anduiza y de Maya (2005) nos ofrecen diversos indicadores cuantitativos al respeto, tanto relativos a la extensión como a la diversidad de participantes. La complejidad de los problemas actuales recomendaría poner más atención en la diversidad que en la extensión. Sin embargo, las crecientes demandas ciudadanas pidiendo espacios más amplios de participación y de decisión aconsejan, al mismo tiempo, combinar los mecanismos focalizados en la diversidad con los enfoques centrados en la extensión. Paralelamente, vivimos una importante crisis de representatividad y de intermediación en todos los niveles (Subirats, 2011), lo que nos obliga también a pensar en criterios e indicadores que nos permitan evaluar en qué medida los discursos de las personas representantes vehiculan los discursos del colectivo al cual representan.

En un contexto de racionalización administrativa es necesario priorizar aquellas iniciativas de participación institucional que aborden temas relevantes y respondan a demandas reales de la ciudadanía. Ambos criterios ya se proponían en la propuesta de Jorba et al. (2007) y entendemos que es del todo pertinente incorporarlos en las evaluaciones de procesos institucionales de participación en el actual contexto de crisis.

Como ya apuntamos, evaluar la forma cómo se participa (y concretamente la forma cómo se delibera) es un elemento muy significativo para hacer frente a problemas complejos de forma participada. En este sentido, tanto la difusión (Font y Blanco, 2006) como la calidad de la información y de la deliberación (Brugué, 2009; Gutmann y Thompson, 2004) son dos criterios que necesariamente debemos incorporar en las evaluaciones (Fishkin, 2009). Al mismo tiempo, sin embargo, debemos de tener en cuenta que la ciudadanía cada vez más reclama espacios de participación vinculados a la toma de decisiones.

Por último, la creciente desconfianza de la ciudadanía hacia la clase política y las instituciones públicas nos obligan a pensar la evaluación de la participación no sólo desde una lógica procedimental sino, sobre todo, desde una lógica funcional (Blanco y Ballester, 2011). La participación debe servir para mejorar la calidad de vida de los ciudadanos y, en un contexto donde los problemas materiales son cada vez más importantes, eso se traduce en procesos participativos que tengan incidencia en la toma de decisiones públicas y que produzcan unos resultados tangibles y aplicables (Fung, 2006). Aun así, si queremos que la participación produzca un verdadero cambio cultural (Brugué, 2004; Subirats, 2003), entonces no podemos dejar de evaluar también algunos impactos intangibles como puede ser el aprendizaje de los participantes o la mejora de sus relaciones.

Para poder operativizar todos estos criterios, se han transformado en una serie de preguntas de evaluación, que se ha intentado que fueran observables, accesibles y simples. Estas preguntas se han asociado a indicadores de evaluación, algunos de 
ellos cuantitativos y otros cualitativos. A continuación se detallan para cada aspecto tratado los criterios, preguntas e indicadores de evaluación y herramientas de recogida de datos (tabla 2).

Tabla 2: Criterios, preguntas e indicadores, y herramientas

\begin{tabular}{|c|c|c|}
\hline Criterio & Preguntas e indicadores de evaluación & Herramientas \\
\hline \multicolumn{3}{|c|}{ Proceso } \\
\hline Acuerdo & Grado de aceptación del proceso & EP, CE \\
\hline $\begin{array}{l}\text { Compromiso } \\
\text { político }\end{array}$ & $\begin{array}{l}\text { Compromiso política claro con los resultados del } \\
\text { proceso }\end{array}$ & OC, AM, EP \\
\hline Coliderazgo & $\begin{array}{l}\text { Liderazgo y coordinación del proceso. Grado de } \\
\text { pluralidad }\end{array}$ & OC \\
\hline $\begin{array}{l}\text { Claridad de los } \\
\text { objetivos }\end{array}$ & $\begin{array}{l}\text { Percepción subjetiva de la claridad de los objeti- } \\
\text { vos y reglas del juego }\end{array}$ & CE \\
\hline Recursos & Recursos empleados en el proceso & EP \\
\hline \multicolumn{3}{|c|}{ Quién participa } \\
\hline \multirow{4}{*}{$\begin{array}{l}\text { Diversidad de } \\
\text { participantes }\end{array}$} & Porcentaje de participantes menores de 35 años & RP, OC, CE \\
\hline & Porcentaje de mujeres & RP, OC, CE \\
\hline & $\begin{array}{l}\text { Presencia de los distintos intereses en relación a } \\
\text { la temática tratada }\end{array}$ & RP, OC, CE, S \\
\hline & Participación del colectivo migrante & RP, OC \\
\hline Extensión & $\begin{array}{l}\text { Porcentaje de personas/organizaciones participan- } \\
\text { tes sobre la población de referencia }\end{array}$ & RP, OC, CE, S \\
\hline Representación & $\begin{array}{l}\text { Grado en que los discursos de las personas } \\
\text { representantes vehiculan los discursos del colec- } \\
\text { tivo al cual representan }\end{array}$ & OC, EP \\
\hline \multicolumn{3}{|c|}{ Sobre qué se participa } \\
\hline Relevancia & $\begin{array}{l}\text { Valoración subjetiva de la población y los agen- } \\
\text { tes }\end{array}$ & CE, EP \\
\hline Criterio & Preguntas e indicadores de evaluación & Herramientas \\
\hline Procedencia & $\begin{array}{l}\text { Grado en que la temática recoge las demandas } \\
\text { procedentes de la ciudadanía }\end{array}$ & EP \\
\hline
\end{tabular}




\begin{tabular}{|c|c|c|}
\hline \multicolumn{3}{|c|}{ Cómo se participa } \\
\hline $\begin{array}{l}\text { Grado de participa- } \\
\text { ción }\end{array}$ & Información y/o deliberación y/o decisión & OC \\
\hline Difusión & $\begin{array}{l}\text { Grado en el que la información ha llegado a los } \\
\text { participantes potenciales }\end{array}$ & CE, EP \\
\hline $\begin{array}{l}\text { Calidad de la } \\
\text { información }\end{array}$ & $\begin{array}{l}\text { Valoración subjetiva de la pluralidad y claridad } \\
\text { de la información recibida }\end{array}$ & $\begin{array}{l}\text { OC, CE, AM, } \\
\text { EP }\end{array}$ \\
\hline \multirow{3}{*}{$\begin{array}{l}\text { Calidad de la } \\
\text { deliberación }\end{array}$} & $\begin{array}{l}\text { Posibilidad de los participantes de poder expresar } \\
\text { sus ideas en los debates }\end{array}$ & \multirow{3}{*}{ OC, CE, EP } \\
\hline & $\begin{array}{l}\text { Posibilidad de poder generar nuevas ideas a partir } \\
\text { del intercambio de puntos de vista y de la delibe- } \\
\text { ración }\end{array}$ & \\
\hline & $\begin{array}{l}\text { Percepción de los participantes del grado de } \\
\text { profundidad del debate }\end{array}$ & \\
\hline \multicolumn{3}{|c|}{ Resultados } \\
\hline \multirow[t]{2}{*}{ Incidencia } & $\begin{array}{l}\text { Existencia de un documento con los resultados } \\
\text { más relevantes del proceso. Grado de influencia } \\
\text { de los participantes en este documento }\end{array}$ & $\mathrm{AM}$ \\
\hline & Valoración subjetiva de los resultados & CE \\
\hline $\begin{array}{l}\text { Supervisión pública } \\
\text { de los resultados }\end{array}$ & Devolución, órganos de seguimiento & $\mathrm{AM}$ \\
\hline \multirow{2}{*}{$\begin{array}{l}\text { Aprendizaje de los } \\
\text { agentes }\end{array}$} & Sesiones de capacitación & OC \\
\hline & Percepción de aprendizaje & CE \\
\hline $\begin{array}{l}\text { Mejora de las } \\
\text { relaciones }\end{array}$ & $\begin{array}{l}\text { Mejora de la capacidad de interlocución de las } \\
\text { organizaciones }\end{array}$ & CE, EP \\
\hline
\end{tabular}

Fuente: elaboración propia S (sociograma), OC (observación cualitativa), EP (entrevistas a participantes clave), AM (análisis de materiales producidos y distribuidos), CE (cuestionarios de evaluación), RP (registro de participantes).

Para responder a cada pregunta y completar los indicadores derivados de ella se han propuesto diversas herramientas metodológicas tanto cuantitativas como cualitativas que se complementan las unas con las otras a partir de una triangulación metodológica que pretende implicar a los participantes del proceso en la evaluación del mismo. Así, se analizaron todos los materiales producidos durante el proceso, se 
distribuyó un cuestionario de evaluación entre todos los participantes ${ }^{4}$, se analizó el registro de participantes, se llevaron a cabo siete entrevistas semi-estructuradas en profundidad a participantes de diversa índole (políticos, técnicos y representantes de distintas organizaciones sociales), se practicaron dos observaciones cualitativas directas durante las sesiones de deliberación y se elaboró de un sociograma de actores y relaciones. En la figura 1 se muestra la temporalización en los usos de las distintas herramientas metodológicas.

Figura 1: Temporalización del uso de las distintitas herramientas metodológicas

\begin{tabular}{|l|l|l|l|l|}
\hline $\begin{array}{l}\text { Herramienta metodológi- } \\
\text { ca (entre paréntesis código } \\
\text { de la herramienta) }\end{array}$ & $\begin{array}{l}\text { Antes del } \\
\text { proceso }\end{array}$ & $\begin{array}{c}\text { Durante el } \\
\text { proceso }\end{array}$ & $\begin{array}{c}\text { Recién termi- } \\
\text { nado el } \\
\text { proceso }\end{array}$ & $\begin{array}{c}\text { Después de la } \\
\text { difusión de los } \\
\text { resultados }\end{array}$ \\
\hline Sociograma (S) & & & & \\
\hline $\begin{array}{l}\text { Observación cualitativa } \\
\text { (OC) }\end{array}$ & & & & \\
\hline $\begin{array}{l}\text { Entrevistas a participan- } \\
\text { tes clave (EP) }\end{array}$ & & & & \\
\hline $\begin{array}{l}\text { Análisis de materiales } \\
\text { producidos y distribuidos } \\
\text { (AM) }\end{array}$ & & & & \\
\hline $\begin{array}{l}\text { Cuestionarios de evalua- } \\
\text { ción (CE) }\end{array}$ & & & & \\
\hline $\begin{array}{l}\text { Registro de participantes } \\
\text { (RP) }\end{array}$ & & & & \\
\hline
\end{tabular}

Fuente: elaboración propia

\section{La Muntanya de Sant Miquel: un ejemplo paradigmático de la participación en la gestión forestal}

El caso de estudio sobre el cual aplicaremos nuestra propuesta metodológica es el proceso participativo sobre el futuro de la Muntanya de Sant Miquel. Este proceso se llevó a cabo durante el mes de mayo de 2010 en el término municipal de Setcases, en la comarca del Ripollès (provincia de Girona). El proceso fue promovido por la Direcció General de Participació Ciutadana de la Generalitat de Catalunya.

${ }^{4}$ De los 39 participantes del proceso 20 respondieron a la encuesta $(51,3 \%)$ 
Entendemos que el caso es de utilidad por diversos motivos. En primer lugar, se trata de un proceso participativo institucional desarrollado en pleno contexto de crisis económica, política y social. Además, es una de las pocas experiencias de participación llevadas a cabo desde la administración autonómica y, al mismo tiempo, tiene un marcado carácter de gobernanza multinivel, pues combina distintas escalas tanto geográficas como administrativas. El proceso es pionero en su ámbito en Cataluña, ya que la normativa actual de ordenación y gestión forestal no prevé la participación ciudadana más allá de los canales habituales de información pública y consulta ${ }^{5}$. Y, por último, como ya hemos comentado anteriormente, el caso de estudio incluyó participantes que se comportaron en base a una lógica de "deliberación caliente", con unas posiciones a priori fuertes, y otros que lo hicieron en una dinámica de "deliberación fría", que acudían al proceso participativo sin unas posiciones prefijadas sobre la solución del mismo.

Antes de pasar a la descripción del proceso y a su evaluación creemos oportuno contextualizar el caso de estudio y la problemática que inició el proceso.

\subsection{Breve trayectoria histórica}

En Cataluña el 72\% de los bosques son de titularidad privada. En este contexto, la Muntanya de Sant Miquel es una de las pocas excepciones del territorio catalán en las que encontramos una extensa superficie forestal de propiedad pública. Se trata de un espacio de casi 4.000 ha -significando alrededor del 80\% del término municipal de Setcases- y es propiedad de la Generalitat de Catalunya, por bien que el Ayuntamiento de Setcases tiene una servidumbre de aprovechamiento forestal y forma parte Plan de Espacios de Interés Natural (PEIN) "Capçaleres del Ter y del Freser" y de la Red Natura 2000. Aparte de la Generalitat y del Ayuntamiento, tienen competencias sobre el espacio el Consorci d'espais d'interès natural del Ripollès (CEINR) y el Consell Comarcal del Ripollès.

Históricamente este bosque ha sido una fuente importante de madera y otros recursos para el municipio y el Valle de Camprodon. Como se muestra en la tabla 3, el bosque ha sido de titularidad del Monasterio de Ripoll, del Estado y de la Generalitat de Catalunya. Desde mediados del siglo XX el municipio de Setcases tiene establecida una servidumbre de extracción de madera y de pastos.

${ }^{5}$ El Plan General de Política Forestal 2007-2016 de la misma Generalitat de Catalunya ya se había hecho de manera participativa pero a una escala superior y no para un bosque concreto. 
Tabla 3: Regímenes e titularidad de la Muntanya de Sant Miquel

\begin{tabular}{|l|l|}
\hline \multicolumn{1}{|c|}{ Periodo } & \multicolumn{1}{c|}{ Titularidad } \\
\hline $\begin{array}{l}\text { Época Medieval hasta } \\
\text { 1886 (Desamortización de } \\
\text { Mendizábal) }\end{array}$ & Monasterio de Ripoll \\
\hline $1886-1994$ & $\begin{array}{l}\text { Estatal (sin embargo sentencia Audiencia de Barcelona en } \\
1914 \text { dando servidumbres de explotación del bosque al } \\
\text { Ayuntamiento de Setcases; en 1952 se materializa el acuerdo } \\
\text { fijando 70m³ de madera anuales como servidumbres) }\end{array}$ \\
\hline 1994-actualidad & Generalitat de Catalunya \\
\hline
\end{tabular}

Fuente: elaboración propia a partir de Direcció General de Participació Ciutadana (2010)

Primero la administración estatal y más tarde la Generalitat han gestionado el bosque con criterios técnicos con el objetivo de compatibilizar la preservación del espacio con los distinto usos del bosque (ganadería, aprovechamiento forestal, ocio, etc.). En la tabla 4 se muestran los distinto proyectos de ordenación forestal que han regido la gestión del bosque.

Tabla 4: Proyectos de ordenación forestal

\begin{tabular}{|c|l|}
\hline 1959 & $\begin{array}{l}\text { Primer proyecto: estructuración del bosque y explotación máxima de } \\
1101 \mathrm{~m}^{3} \text { anuales }\end{array}$ \\
\hline 1974 & $\begin{array}{l}1^{\text {a }} \text { Revisión: reducción explotación máxima madera a } 987 \mathrm{~m}^{3} \text {, se incluyen } \\
\text { actividades de ocio compatibles con las del sector primario, y se } \\
\text { establecen áreas de carácter protector donde no se planifican talas }\end{array}$ \\
\hline $\begin{array}{c}2004 \\
\text { (vigencia } \\
\text { hasta 2015) }\end{array}$ & $\begin{array}{l}2^{\text {a }} \text { Revisión: criterios de gestión forestal sostenible (se ve reconocida con } \\
\text { los certificados PEFC en } 2007 \text { y FSC en 2009), protección y gestión de la } \\
\text { fauna y de sus hábitats }\end{array}$ \\
\hline
\end{tabular}

Fuente: elaboración propia a partir de Direcció General de Participació Ciutadana (2010)

\subsection{El conflicto y la apertura del proceso participativo}

Si bien la gestión forestal vigente intenta compatibilizar los distintos usos del bosque esto no ha sido siempre posible. Una tala de árboles en la zona de la Baga de Carboners, en la Muntanya de Sant Miquel, en el marco de unos trabajos de gestión forestal supuso el detonante de un conflicto entre los distintos actores del territorio. A raíz de este conflicto el por entonces Departamento de Medio Ambiente y Vivienda y la Dirección General de Participación Ciudadana, los dos de la Generalitat 
de Catalunya, decidieron abrir un proceso participativo con los siguientes objetivos (Direcció General de Participació Ciutadana, 2010:2):

- dar a conocer los instrumentos de planificación y gestión forestal vigentes;

- someter estos instrumentos a la deliberación de la sociedad civil;

- analizar posibles mejoras en la gestión forestal;

- e incorporar a la ciudadanía en la planificación y gestión forestal.

Según la Generalitat, con esta iniciativa se pretendía "seguir implicando a la ciudadanía en las políticas ambientales con el fin de enriquecerlas y de encontrar los principales consensos y disensos” (Direcció General de Participació Ciutadana, 2010:2).

Para llevar a cabo el proceso participativo sobre la Muntanya de Sant Miquel se identificaron y convocaron a los agentes más relevantes relacionados con el bosque ${ }^{6}$. El proceso en cuestión se estructuró en dos jornadas, el 15 y el 29 de mayo de 2010. Previamente se habían identificado mediante un mapa de actores y convocado a los agentes relevantes. En la primera jornada tuvo lugar un taller a cargo de dos expertos y una salida de campo a la Baga de Carboners, el punto dónde se originó el conflicto. Esta primera jornada tuvo como objetivo dar a conocer los valores del bosque, y así dar unos conocimientos previos a la segunda jornada, que fue de debate y deliberación, con una lógica de trabajo deductiva, pasando del trabajo individual, al debate en grupo y finalmente al debate plenario. Más allá de estas dos jornadas, que constituyen el núcleo del proceso participativo se tiene que mencionar el espacio de debate y participación juvenil que se abrió en el Instituto Germana Vila Riera de Camprodon, con la participación de unos 36 jóvenes de 15-16 años. Una jornada informativa dio lugar a un debate 2.0 en las redes sociales y un posterior debate presencial que finalizó con la redacción de un manifiesto.

\section{Los resultados de la evaluación}

A continuación se presentan los resultados más relevantes para cada aspecto analizado. Estos son analizados no sólo en clave del proceso concreto sino también en función de su mayor o menor importancia en el contexto actual y su utilidad para otros procesos participativos de distinta índole.

${ }^{6}$ Los agentes (locales) convocados incluían entidades ecologistas y conservacionistas, el sector agroforestal, el sector turístico y la administración local. Sin embargo el proceso estaba abierto a todos los ciudadanos que desearan participar en el él. Ver tabla 6 para conocer el número exacto de participantes de cada grupo de agentes. 


\subsection{Coordinación del proceso}

En referencia al grado de acuerdo sobre la necesidad de realizar el proceso participativo, se puede decir que en términos generales fue ampliamente aceptado por los agentes que participaron en él. Más de un $75 \%$ de los encuestados tacharon el proceso de "muy importante", mientras que el resto lo calificó como "importante". De las entrevistas sin embargo se desprende una visión más crítica: algunos agentes clave cuestionaron la necesidad de realizar tal proceso si ya existía una resolución del Parlamento Catalán instando a la Generalitat a proteger este espacio. Sin embargo, estos mismos miembros se congratulan que este proceso haya llevado a desenterrar el proyecto de Parque Natural y a tomar consciencia de la problemática.

El coliderazgo del proceso por dos departamentos distintos (Dirección General de Participación Ciudadana y Departamento de Medio Ambiente y Vivienda), junto al hecho que el anfitrión del proceso (el ayuntamiento de Setcases) no actuaba como líder, llevó a algunos agentes a no percibir de manera clara el liderazgo del proceso. Sin embargo se destaca el importante compromiso político de los distintos agentes propulsores del proceso, especialmente de la Dirección General de Participación Ciudadana y del Departamento de Medio Ambiente y Vivienda. Esto se plasmó con la presencia de diferentes cargos políticos durante el proceso y con el compromiso de estos de recoger los resultados del proceso participativo.

La claridad de los objetivos es uno de los puntos más débiles detectados del proceso. Alrededor de un $40 \%$ de los encuestados afirmaban que los objetivos del proceso habían sido poco o nada claros. Esta opinión era compartida por la mayor parte de los entrevistados. Frente a estos resultados, argumentamos que uno de los principales puntos débiles que ha podido tener el proceso es el desajuste de escala entre el diseño inicial del proceso y los resultados finales; esto ha podido difuminar e introducir confusión en los objetivos. El proceso fue iniciado como respuesta a un conflicto alrededor de unos usos muy específicos (tala de árboles) en un lugar muy concreto (Baga de Carboners). Posteriormente, sin embargo, a lo largo del proceso participativo esta escala inicial se trascendió llegándose a debatir sobre la creación de un Parque Natural que incluiría distintos municipios.

Los recursos destinados al proceso fueron óptimos de acuerdo con las entrevistas y las encuestas. Sin embargo, algunos participantes enfatizaron que dada la complejidad de la temática tratada se habría necesitado una tercera jornada para tener más tiempo para la reflexión. El problema señalado anteriormente sobre el desajuste de escala, también tuvo un impacto en la inadecuada dimensión temporal del proceso.

La evaluación nos muestra, a través de los participantes, que el proceso analizado cumplió con algunos de los parámetros de coordinación esenciales para evitar que este tipo de mecanismos institucionales reviertan en un incremento de la desconfianza de la ciudadanía hacia la clase política y las instituciones públicas: un elevado grado de acuerdo sobre la necesidad de llevar a cabo el proceso y un claro compromiso político con los resultados. Al mismo tiempo, sin embargo, la evaluación también pone de relieve algunas debilidades del proceso altamente contrapro- 
ducentes en un contexto como el actual. La falta de claridad en los objetivos puede conducir a los participantes a pensar que "están perdiendo el tiempo" o que "aquello que están haciendo no servirá para nada”, lo que puede incrementar su desconfianza hacia las instituciones. Al mismo tiempo, tanto la falta de claridad en los objetivos como la escasez de los recursos destinados al proceso pueden poner en duda su funcionalidad y la calidad del debate. Para abordar la deliberación de problemas complejos la disponibilidad de tiempo es un recurso importante que no podemos menoscabar.

\section{2. ¿Quién participa?}

Participaron 21 personas en la primera jornada del proceso participativo (salida de campo) y 32 en la segunda (debate). En total el proceso participativo atrajo a 39 participantes distintos, 14 de los cuales asistieron a las dos jornadas. Otra vez nos remitimos a la problemática de la escala. Así, si sólo evaluamos la representación de los agentes a la escala inicialmente planteada por el proceso (la Baga de Carboners y la Muntanya de Sant Miquel) podemos afirmar que la convocatoria de agentes fue muy exhaustiva y completa, y sólo se destaca la baja presencia de propietarios forestales y empresas explotadoras de la madera, representantes del sector turístico y del sector ganadero, y más ciudadanos del municipio (paradójicamente, mientras la celebración del proceso en fin de semana facilitó la presencia de muchos participantes, tuvo un impacto negativo en la presencia de ciudadanos del municipio anfitrión debido a que buena parte de la población se dedica a la restauración y a actividades turísticas). Sin embargo, dada la dimensión final del proceso, la temática sobrepasó la escala municipal y del Valle de Camprodon. En este sentido, si nos basamos en esta escala final, en el proceso faltaron algunos agentes clave, como los alcaldes de los municipios afectados por un futuro Parque Natural, así como los representantes de la administración comarcal.

La diversidad de los participantes también es un aspecto importante para evaluar la calidad de un proceso participativo. En este sentido la presencia de grupos susceptible de ser excluidos de estos procesos (inmigrantes, mujeres y población joven) es uno de los indicadores básicos para evaluar tal diversidad. En la tabla 5 se compara la participación de tales grupos en relación a su peso en el municipio y en la comarca del Ripollès. En lo que respeta a la población joven y las mujeres el proceso tuvo una representación equilibrada (recordemos que el proceso participativo también tuvo lugar en el instituto de secundaria). Sin embargo, la representación del colectivo inmigrante fue nula. 
Tabla 5: Indicadores socio-demográficos Ripollès, Setcases y proceso participativo

\begin{tabular}{|l|l|l|c|c|c|}
\hline & Setcases & Ripollès & \multicolumn{1}{|c|}{$\begin{array}{c}\text { Proceso } \\
\text { participativo } \\
\left(\mathbf{1}^{\text {a }} \text { jornada) }\right.\end{array}$} & $\begin{array}{c}\text { Proceso } \\
\text { participativo } \\
\left(\mathbf{2}^{\mathrm{a}} \text { jornada) }\right.\end{array}$ & $\begin{array}{c}\text { Proceso partici- } \\
\text { pativo IES } \\
\text { Camprodon }\end{array}$ \\
\hline $\begin{array}{l}\text { Población } \\
\text { inmigrada } \\
\text { (2009) }\end{array}$ & $9,83 \%$ & $8,80 \%$ & \multicolumn{2}{|c|}{$0 \%$} & - \\
\hline $\begin{array}{l}\text { Población } \\
\text { <35 años } \\
\text { (2009) }\end{array}$ & $26,59 \%$ & $34,88 \%$ & Aprox. 25\% & Aprox. 25\% & $\begin{array}{c}\text { Todos (entre } 15 \\
\text { y 17 años) }\end{array}$ \\
\hline $\begin{array}{l}\text { Población } \\
\text { femenina } \\
\text { (2009) }\end{array}$ & $44,50 \%$ & $49,80 \%$ & $38 \%$ & $40 \%$ & $48,4 \%$ \\
\hline
\end{tabular}

Fuente: elaboración propia a partir de datos de IDESCAT y trabajo de campo

A su vez es interesante analizar la presencia de distintos intereses en relación a la temática tratada. Como se puede observar en la tabla 6 la mayor parte de los participantes participaron en el proceso representando organizaciones o entidades, mientras que alrededor de una tercera parte vino a título individual.

Tabla 6: Tipología de participantes

\begin{tabular}{|l|c|c|}
\hline & $\begin{array}{c}\text { Jornada 15 mayo } \\
\mathbf{2 0 1 0}\end{array}$ & $\begin{array}{c}\text { Jornada 29 mayo } \\
\mathbf{2 0 1 0}\end{array}$ \\
\hline Sector agroforestal & $5 \%$ & $6 \%$ \\
\hline Entidad ecologista/conservacionista & $18 \%$ & $19 \%$ \\
\hline Sector turístico & $5 \%$ & $6 \%$ \\
\hline Administración local & $32 \%$ & $28 \%$ \\
\hline A título individual & $35 \%$ & $32 \%$ \\
\hline Otros & $5 \%$ & $9 \%$ \\
\hline
\end{tabular}

Fuente: elaboración propia

En último lugar, es interesante analizar en qué medida los discursos de los participantes que representaban entidades u organizaciones vehiculan los discursos de tales entidades. Mediante la observación directa durante el proceso y las entrevistas a posteriori se constató que los participantes reproducen y articulan en gran medida los discursos oficiales y directrices de sus organizaciones. En este sentido, las organizaciones reconocen que se mantuvieron procesos de debate interno previo al 
proceso así como un seguimiento $a$ posteriori para hacer llegar la información a todos los miembros de la entidad, lo que también denota un planteamiento de deliberación caliente en el que los actores refuerzan sus posiciones. Sin embargo se detectó que algunos participantes formaban parte de más de un colectivo y finalmente su postura reflejaba estrictamente su opinión personal.

Como ya apuntamos, el proceso analizado combina elementos de deliberación caliente con elementos de deliberación fría. Desde el punto de vista de la deliberación caliente la evaluación nos muestra, con algunos matices en función de la escala de análisis, que los principales actores con intereses en el tema sometido a debate estuvieron presentes en el proceso. Si analizamos el proceso desde el punto de vista de la deliberación fría vemos como, efectivamente, esta también estuvo presente. Sin embargo, podríamos discutir si es o no suficiente que una tercera parte de los participantes acudan al proceso participativo a título individual (frente a las dos terceras partes que tenían unas posiciones claras y preestablecidas) y si el conjunto de participantes (39 en total) es suficientemente exhaustivo o no.

\section{3. ¿Sobre qué se participa?}

La práctica totalidad de los encuestados afirma que la temática tratada era muy relevante dado que se trata de uno de los pocos bosques públicos gestionados por la Generalitat de Catalunya. Las entrevistas coinciden en señalar la relevancia de la temática y capturan el deseo que estos procesos se extiendan a otros ámbitos. Es clave, sin embargo, reflexionar otra vez sobre el cambio de escala del proceso participativo. De la pregunta inicial "qué gestión forestal se quiere” para la Muntanya de Sant Miquel, se pasó a preguntar "qué figura de protección se quiere” para un ámbito que superaba con creces el inicial.

Los entrevistados también están de acuerdo con el hecho que la temática objeto de participación recogía las demandas procedentes de la ciudadanía. Esta opinión era especialmente compartida por las entidades ecologistas y aquellas dedicadas a la promoción del territorio. Estas entidades reconocen que desde un inicio deseaban que el proceso se convirtiera en una herramienta para reactivar las demandas sobre la creación de una Parque Natural. En consecuencia, acudían al debate con una posición prefijada bastante rígida, hecho muy característico de una deliberación caliente. Según ellos la problemática que originó el proceso (la tala de árboles en la Baga de Carboners) no se podía desvincular de la demanda de cambiar el nivel de protección.

Uno de los puntos débiles señalados por algunos de los entrevistados fue la superficialidad del debate entre expertos. Algunos participantes subrayaron el déficit de información sobre las implicaciones de implementar la figura de Parque Natural o Parque Nacional. De nuevo, esta problemática está estrechamente ligada al tema de la escala del proceso previamente planteado. En este sentido estos participantes argumentan que si el objetivo era debatir de forma abierta sobre los distintos modelos y figuras de protección (gestión forestal, Parque Natural o Parque Nacional) se 
podría haber planteado desde un buen inicio. De esta manera los objetivos habrían sido más transparentes y claros desde un principio y no hubiera existido la percepción de ligera “desinformación” y confusión. Independientemente de la escala adoptada, algunos participantes también destacaban la poca pluralidad de los expertos que participaron en el proceso.

En el contexto actual en el que parece que las iniciativas institucionales deben pasar por un proceso de racionalización resulta crucial que los temas sometidos a participación sean relevantes. La evaluación llevada a cabo muestra cómo, efectivamente, el proceso analizado trata sobre un tema que lo es, o por lo menos así lo entienden los que participaron en el proceso. Sin embargo, la evaluación también pone de relieve que no es suficiente que el tema sea relevante sino también que el enfoque adoptado y la información aportada sean adecuados. De lo contrario el proceso puede pecar de poca claridad, de poca diversidad y de una deliberación deficiente; tres aspectos que son de gran importancia para hacer frente a la crisis de la política.

\section{4. ¿Cómo se participa?}

Uno de los puntos clave de la evaluación es analizar el grado de participación e implicación que fomentó el proceso. De la observación cualitativa podemos afirmar que en este caso el proceso mostró su intención clara de ir más allá de la mera información (básicamente en la primera jornada) para llegar a la deliberación colectiva e incluso caminar hacia una proceso de toma de decisiones colectivo (se hizo patente durante la segunda jornada). Las encuestas confirman esta interpretación y evocan también un alto grado de satisfacción con el nivel de participación e implicación de los participantes.

En lo que concierne a la calidad de la deliberación, se destaca que si a priori todos los participantes tenían las mismas oportunidades de expresar sus ideas en el debate, en la práctica la asimetría en el grado de conocimientos sobre el tema llevó a algunos participantes a modular y controlar el debate. A su vez también destacamos la dicotomía entre los intereses particulares y los intereses colectivos, llegando a una polarización en algunos momentos del debate entre partidarios de la gestión forestal y entidades ecologistas, quedando el resto de los participantes en un espacio intermedio. Aunque algunos entrevistados percibían que el proceso no tuvo éxito en crear la posibilidad de generar nuevas ideas a partir del intercambio de puntos de vista y de la deliberación (porque las posiciones iniciales de algunos actores estaban muy enrocadas) la realidad es que la solución finalmente adoptada (el compromiso de estudiar más profundamente la creación del Parque Natural) fue ampliamente aceptada por todos los actores.

La difusión que tuvo el proceso fue bien valorada por los encuestados (30\% muy satisfechos; $65 \%$ bastante satisfechos). Todo el proceso fue acompañado de un plan de comunicación que incluía distintos canales de divulgación (página Web, documentación divulgativa, notas de prensa, etc.). Por partes casi iguales los parti- 
cipantes conocieron la existencia del proceso a través de sus entidades $(27,3 \%)$, a través del ayuntamiento (27,3\%), del boca-oreja (27,3\%) y a través de Internet (18,1\%). Algunos participantes manifestaron que la convocatoria fue "demasiado digital” y que muchos vecinos del Valle de Camprodon sin acceso a Internet no recibieron la convocatoria. Vemos que el impacto de la comunicación a través de la prensa resultó nulo, lo que hace replantear la utilidad de este canal para futuros procesos. Otra vez tenemos que remitirnos al problema de escala. Si atendemos al objetivo inicialmente planteado, la difusión de la convocatoria fue adecuada; no es así, sin embargo, si nos fijamos en la magnitud final del proceso, tratando una temática estratégica para todo el valle y la comarca.

La evaluación sobre el "cómo" se participa puso de relieve la importancia de la deliberación en los procesos participativos y, al mismo tiempo, mostró las dificultades de encaje entre dos lógicas deliberativas (fría y caliente) que cada vez más se van a ver forzadas a convivir entre sí. Una deliberación de calidad debe evitar reproducir las desigualdades de recursos entre los participantes, un reto que resulta enormemente difícil cuando se combinan lógicas de deliberación fría con lógicas de deliberación caliente.

\subsection{Las consecuencias de la participación}

La primera constatación que se puede hacer de los resultados del proceso, y que recae en el problema de escala, es que mientras los objetivos y el planteamiento inicial del procesos fueron parciales (gestión forestal en un espacio específico y reducido) la solución ha sido global (propuesta de figura de Parque Natural). En este sentido la discusión no se centró en si la gestión forestal se hacía bien o no, sino en discutir si en el territorio existían unos valores que requerían una figura de protección superior a la existente. Un entrevistado argumentaba que primero se tiene que consensuar qué nivel de protección se quiere y después ya vendrá el modelo de gestión; en cambio el proceso siguió la ruta inversa. De todos modos la mayor parte de los encuestados (73\%) afirma que se lograron los objetivos en un buen grado. De manera más general, las encuestas revelan que los participantes, en gran medida, quedaron satisfechos con los resultados del proceso.

En lo referente a la incidencia del proceso se remarca la elaboración y distribución de un documento de resultados. La mayor parte de los participantes se identifican con los resultados finales. Sin embargo el proceso recibió ciertas críticas por la poca concreción de las conclusiones. De manera muy remarcable destacamos el hecho que la gran totalidad de los encuestados mostraron un interés alto para participar en otros procesos participativos.

Por lo que respeta a la supervisión pública de los resultados una gran parte de ellos afirmó que el proceso participativo sería útil para influenciar en las decisiones que se tomarían a posteriori. Sin embargo, para muchos de los entrevistados el resultado final del proceso no dará respuesta al objetivo inicialmente planteado 
hasta que no se declare la zona Parque Natural y el área dónde se inició el conflicto sea declarada Reserva Integral.

De las entrevistas y de las encuestas se infiere que el aprendizaje derivado del proceso aparece como otro de los puntos débiles. En lo que se refiere a la mejora de las relaciones, podemos decir que muchos entrevistados coinciden en destacar que el proceso ayudó por un lado a mejorar la capacidad de interlocución entre las distintas entidades, y por el otro entre ellas y la administración pública. Muchas de estas organizaciones ya trabajaban en red antes del proceso. Esto se plasmó, por ejemplo, en la redacción de un manifiesto conjunto por parte de las organizaciones ecologistas, hecho que, de nuevo, responde a un modelo de deliberación caliente en el que los actores acuden a la deliberación con posiciones rígidas y prefijadas.

Vemos como, pese a la desconfianza de la ciudadanía con la clase política y las instituciones públicas, los ciudadanos están dispuestos a participar en las iniciativas de participación institucional. Además, si ésta se realiza bajo unos determinados parámetros de calidad (como es el caso) entonces muestran su disponibilidad a volver a participar. Resulta fundamental, sin embargo, que los procesos de participación institucional no sólo culminen en unos resultados tangibles, cosa que ocurrió en el caso analizado, sino que estos sean además concretos, aplicables y aplicados.

\section{Conclusiones finales}

Mediante el caso de estudio sobre el futuro de la Muntanya de Sant Miquel hemos querido presentar un ejemplo práctico sobre cómo se puede evaluar un proceso participativo en el actual contexto de crisis económica, política y social. La evaluación se ha llevado a cabo utilizando una metodología integral, analizando tanto el proceso como sus resultados, implicando a los participantes en la evaluación y poniendo el acento en la calidad de la deliberación y los efectos de la participación; dos elementos de gran importancia en el contexto actual.

Entendemos que esta evaluación puede ser de utilidad como modelo a replicar en otras experiencias $y$, al mismo tiempo, nos ofrece algunas indicaciones sobre elementos a tener en cuenta en futuros procesos participativos. Además, la evaluación también nos ha sido de utilidad para analizar las consecuencias de un elemento que, a nuestro juicio, puede ser de gran relevancia para entender el funcionamiento (y también el éxito o el fracaso) de las distintas experiencias participativas en el contexto actual: nos referimos a la temperatura de la deliberación. Como hemos visto, entender las distintas circunstancias en las que se desarrollan los procesos participativos puede ser de utilidad para mejorar su propio diseño.

En este apartado final del artículo abordamos dos grandes cuestiones. En primer lugar sistematizamos las fortalezas y las debilidades del estudio de caso evaluado y proponemos algunas mejoras. Por último, retomamos el debate sobre la temperatura de la deliberación y analizamos el estudio de caso desde esta perspectiva, aportando algunas reflexiones que pueden ser de interés tanto a nivel analítico como a nivel aplicado. 


\subsection{Fortalezas, debilidades y recomendaciones de mejora}

La evaluación de los procesos participativos, si sirve para aportar mejoras a la participación, puede contribuir también a hacer de estos procesos verdaderas herramientas que acerquen a la ciudadanía a los asuntos que más la conciernen. En la tabla 7 se presentan de manera esquemática las fortalezas y debilidades más relevantes del proceso analizado, así como las recomendaciones generales para la mejora de futuros procesos participativos.

Tabla 7: Recomendaciones de mejora

\begin{tabular}{|c|c|c|c|}
\hline $\begin{array}{l}\text { Dimensión } \\
\text { del proceso }\end{array}$ & Fortalezas & Debilidades & $\begin{array}{c}\text { Recomendaciones de } \\
\text { mejora }\end{array}$ \\
\hline $\begin{array}{l}\text { Coordinación } \\
\text { del proceso }\end{array}$ & $\begin{array}{l}\text { Gran aceptación del } \\
\text { proceso } \\
\text { Elevado compromiso } \\
\text { político } \\
\text { Recursos adecuados }\end{array}$ & $\begin{array}{l}\text { Liderazgo poco claro } \\
\text { del proceso } \\
\text { Falta de claridad } \\
\text { entorno a los objetivos } \\
\text { del proceso }\end{array}$ & $\begin{array}{l}\text { Tener en cuenta las } \\
\text { cuestiones de escala: la } \\
\text { escala del proceso tiene } \\
\text { que concordar con los } \\
\text { objetivos }\end{array}$ \\
\hline $\begin{array}{l}\text { Quién } \\
\text { participa }\end{array}$ & $\begin{array}{l}\text { Buena representación } \\
\text { de los agentes de } \\
\text { acuerdo con la escala } \\
\text { inicial del proceso } \\
\text { Buena representación } \\
\text { de colectivos jóvenes } \\
\text { y mujeres }\end{array}$ & $\begin{array}{l}\text { Baja participación de } \\
\text { la población local } \\
\text { Presencia nula del } \\
\text { colectivo inmigrante } \\
\text { Baja presencia de } \\
\text { alcaldes de la zona }\end{array}$ & $\begin{array}{l}\text { Incentivar la participación } \\
\text { de la población local y del } \\
\text { colectivo inmigrante } \\
\text { (teniendo en cuenta las } \\
\text { especificidades de cada } \\
\text { grupo) } \\
\text { Involucrar a la administra- } \\
\text { ción local en el proceso }\end{array}$ \\
\hline $\begin{array}{l}\text { Temática } \\
\text { sobre la que se } \\
\text { participa }\end{array}$ & $\begin{array}{l}\text { Temática muy } \\
\text { relevante } \\
\text { El proceso responde } \\
\text { a una demanda de la } \\
\text { ciudadanía }\end{array}$ & $\begin{array}{l}\text { Déficits de ciertas } \\
\text { informaciones }\end{array}$ & $\begin{array}{l}\text { Fijar y definir claramente } \\
\text { la escala del proceso antes } \\
\text { de su inicio } \\
\text { Pluralidad en la participa- } \\
\text { ción de expertos }\end{array}$ \\
\hline $\begin{array}{r}\text { Dimensión } \\
\text { del proceso }\end{array}$ & Fortalezas & Debilidades & $\begin{array}{c}\text { Recomendaciones de } \\
\text { mejora }\end{array}$ \\
\hline $\begin{array}{l}\text { Cómo } \\
\text { participa }\end{array}$ & $\begin{array}{l}\text { Grado de participa- } \\
\text { ción e implicación de } \\
\text { los participantes } \\
\text { Adecuada difusión de } \\
\text { acuerdo con la escala } \\
\text { inicial planteada }\end{array}$ & $\begin{array}{l}\text { Momentos del debate } \\
\text { monopolizados por } \\
\text { ciertos agentes } \\
\text { Poca pluralidad en los } \\
\text { materiales informati- } \\
\text { vos distribuidos }\end{array}$ & $\begin{array}{l}\text { Definir y transmitir } \\
\text { claramente las preguntas y } \\
\text { los objetivos del debate } \\
\text { desde el comienzo del } \\
\text { proceso } \\
\text { Hacer coparticipes a los }\end{array}$ \\
\hline
\end{tabular}




\begin{tabular}{|c|c|c|c|}
\hline $\begin{array}{l}\text { Dimensión } \\
\text { del proceso }\end{array}$ & Fortalezas & Debilidades & $\begin{array}{c}\text { Recomendaciones de } \\
\text { mejora }\end{array}$ \\
\hline & $\begin{array}{l}\text { Existencia de una } \\
\text { evaluación externa } \\
\text { del proceso participa- } \\
\text { tivo }\end{array}$ & $\begin{array}{l}\text { durante el proceso } \\
\text { Falta de tiempo para } \\
\text { un debate más profun- } \\
\text { do }\end{array}$ & $\begin{array}{l}\text { participantes en la produc- } \\
\text { ción de materiales } \\
\text { Dimensionar temporal- } \\
\text { mente el proceso confor- } \\
\text { me a los objetivos de este }\end{array}$ \\
\hline Resultados & $\begin{array}{l}\text { El proceso ha dado a } \\
\text { conocer el interés de } \\
\text { los procesos partici- } \\
\text { pativos entre los } \\
\text { participantes }\end{array}$ & $\begin{array}{l}\text { Falta de unas conclu- } \\
\text { siones específicas al } \\
\text { final del proceso } \\
\text { Falta de órganos de } \\
\text { seguimiento de los } \\
\text { resultados }\end{array}$ & $\begin{array}{l}\text { Un proceso participativo } \\
\text { debe tener una continui- } \\
\text { dad: tiene que ser un } \\
\text { "punto y seguido" y no un } \\
\text { "punto y final" }\end{array}$ \\
\hline GENERAL & $\begin{array}{l}\text { Proceso pionero en el } \\
\text { ámbito forestal a } \\
\text { escala local } \\
\text { Proceso pionero en el } \\
\text { involucramiento de } \\
\text { jóvenes y de nuevas } \\
\text { tecnologías de la } \\
\text { información }\end{array}$ & $\begin{array}{l}\text { El proceso surge de un } \\
\text { conflicto } \\
\text { Existe un problema de } \\
\text { escala geográfica: la } \\
\text { escala final supera a la } \\
\text { escala inicial plantea- } \\
\text { da }\end{array}$ & $\begin{array}{l}\text { Llevar a cabo los procesos } \\
\text { participativos en tiempos } \\
\text { de baja conflictividad para } \\
\text { evitar la crispación en el } \\
\text { debate } \\
\text { Definir claramente los } \\
\text { límites geográficos del } \\
\text { proceso desde un inicio }\end{array}$ \\
\hline
\end{tabular}

Fuente: elaboración propia

De manera general se destaca el hecho que el proceso es pionero en el ámbito forestal a escala local, así como también es pionero en involucrar a los jóvenes (mediante el proceso paralelo en el Instituto, que no es objetivo de este artículo) y usar de manera innovadora las tecnologías de la información. Como contrapartida se destaca que el proceso fue abierto a raíz de un conflicto. A su vez esto llevó a una indefinición de los objetivos. El proceso se puso en marcha como respuesta a un conflicto específico en un lugar muy concreto (Baga de Carboners) pero ya incluía la discusión sobre el futuro de un ámbito más grande (Muntanya de Sant Miquel). Sin embargo la escala geográfica aumentó y durante el proceso se debatió sobre la posibilidad/necesidad de crear un Parque Natural o Parque Nacional que incluiría diversos municipios de la zona.

\subsection{Retomando el debate sobre la temperatura de la deliberación}

El proceso participativo evaluado se origina a partir de un conflicto, y por tanto parte de un escenario de deliberación “caliente”. Sin embargo, en general el proceso se desarrolló en un clima de baja conflictividad y, de hecho, no se identificaron 
posiciones radicalmente opuestas entre la mayoría de los participantes. Aún así, hubo dos actores (los partidarios de la gestión forestal por un lado y las entidades ecologistas por el otro) que mantuvieron unas posiciones más enrocadas y contribuyeron a aumentar la temperatura de la deliberación en algunos instantes. Además estos dos actores poseían un mayor grado de conocimiento experto y en algunos momentos dificultaban que el resto de participantes opinara en condiciones de igualdad. Aunque estos dos actores pudieran monopolizar el debate puntualmente, el resto de los participantes (la mayoría) no tenían una posición prefijada sobre esta cuestión, no tenían un interés fuerte por defender ninguna de las dos opciones y tampoco poseían un conocimiento experto sobre la materia. Así, la mayoría de los participantes se comportaron bajo una lógica de deliberación "fría". El caso evaluado, pues, mezcló actores que actuaban bajo parámetros de deliberación fría con actores que se comportaron en términos de deliberación caliente. La dificultad, pues, residió en hacer compatibles ambas lógicas.

La asimetría de conocimientos entre los participantes fue el principal factor que distorsionó la calidad de la deliberación. Por lo demás, la deliberación se produjo desde la igualdad, con un intercambio de razones basado en el respeto mutuo y produciendo una solución que claramente responde a una lógica de interés colectivo. A diferencia de lo que suele ocurrir en contextos de deliberación caliente, el debate no cayó en la mera negociación entre intereses particulares. Aunque algunos actores se enrocaron en sus posiciones iniciales, el hecho que la mayoría de los participantes tuvieran la mente más abierta y abordaran el debate como una deliberación fría facilitó la adopción de una solución final de consenso ampliamente aceptada por todos. En este sentido, pues, la deliberación fría se impuso sobre la caliente.

Aunque se llegó a una solución de consenso, las conclusiones finales fueron muy poco concretas y esto suscitó las críticas de buena parte de los participantes. La concreción de los resultados requeriría corregir la mayoría de los problemas que hemos identificado en relación al cambio de escala geográfica que sufrió el proceso: participantes adecuados a la nueva escala, información relativa a la solución propuesta, análisis técnico-jurídico de la viabilidad de la misma, etc.

Concluimos que, efectivamente, en un contexto de deliberación fría es más posible que el debate se desarrolle bajo ciertos parámetros de calidad deliberativa, con un predominio de la lógica del interés colectivo por encima de la lógica de negociación entre intereses particulares. En la deliberación caliente se da todo lo contrario (ver Brugué y Parés, 2012) y, como hemos visto, suelen generarse grandes desigualdades entre los participantes en función de sus conocimientos sobre el tema sometido a participación.

El gran interrogante que nos abre esta investigación es sobre la posibilidad de combinar la deliberación fría con la deliberación caliente. El caso nos muestra que esta combinación resulta extremadamente difícil y no puede producirse sin consecuencias (ya sea en la calidad del debate o en la solidez de los resultados). Querer incorporar al público en general (ciudadanía sin intereses fuertes) cuando el tema tratado responde a un conflicto fuerte entre actores con altos niveles de conocimiento puede generar desigualdades en la deliberación y es posible que la aportación 
sustantiva sobre los resultados sea insignificante. Sin embargo, cuando el tema a abordar requiera ser abordado desde la lógica del interés colectivo porque afecta al conjunto de una comunidad -como es el caso de la experiencia evaluada- entonces la incorporación de elementos de deliberación fría puede ser del todo necesaria. En estos casos el reto será hallar el diseño y la dinamización adecuados para compatibilizar ambas lógicas, llevando la deliberación hacia una temperatura de equilibrio. En el caso evaluado la combinación de ambas lógicas no ha sido del todo satisfactorias -se han generado desigualdades deliberativas y el resultado ha sido confuso-, sin embargo, podemos afirmar que al final se ha llegado a una solución de equilibrio.

\section{Agradecimientos}

Se quiere agradecer la financiación recibida por parte de la Direcció General de Participació Ciudadana de la Generalitat de Catalunya para realizar la evaluación del estudio de caso en el año 2010. En el periodo 2012-2014 Hug March ha recibido financiación del Ministerio de Economía y Competividad (JCI- 2011-10709). Finalmente se quiere agradecer el tiempo que nos concedieron todos los encuestados y entrevistados y también la ayuda proporcionada por Laura Suñé a lo largo del proceso de evaluación. 


\section{Bibliografía}

Ackerman, B. y Fishkin, J. (2004) Deliberation day, New Haven, Yale University.

Alguacil, J. (2006) "Los desafíos del nuevo poder local: ¿hacia una estrategia relacional y participativa en el gobierno de la ciudad?”, en: J. Alguacil, ed., Poder Local y Participación Democrática, Madrid, El Viejo Topo.

Alvira, F. (1996) Metodología de la evaluación de programas, Madrid, Centro de Investigaciones Sociológicas.

Anduiza, E. y De Maya, S. (2005) La Qualitat en la Participació: una proposta d'inicadors, Barcelona, Fundació Jaume Bofill.

Arnstein, S. (1969) “A ladder of citizen participation" Journal of the American Institute of Planners 35(4): 216-224.

Blanco, I. y Ballester, M. (2011) “¿Participar para transformar? La experiencia de los Presupuestos Participativos en la provincia de Barcelona” Gestión y Análisis de Políticas Públicas 5:117-144.

Blanco, I.; Lowndes, V. y Pratchett, L. (2011) "Policy networks and governance networks: towards greater conceptual clarity” Political Studies Review 9: 297208.

Bobbio, L. (2010) “Types of deliberation” Journal of Public Deliberation 6(2): 124.

Bobbio, L. y Pomatto, G. (2007) "Modelli di coinvolgimento dei cittadini nelle scelte pubbliche” Informe para la Provincia Autonoma di Trento, inédito.

Brugué, Q. (2009) "Calidad democrática: de la debilidad liberal a la fuerza deliberativa”, en M. Parés, coord., Participación y calidad democrática. Evaluando las nuevas formas de democracia participativa, Barcelona, Editorial Ariel.

Brugué, Q. (2004) "Modernizar la administración desde la izquierda: burocracia, nueva gestión pública y administración deliberativa" Revista del CLAD. Reforma y Democracia 29: 1-16.

Brugué, Q. y Parés, M. (2012) "Entre la deliberación y la negociación: el caso de la Mesa de la Montaña en Aragón” Revista de Estudios Políticos 158: 55-101.

Castellà, C. y Jorba, L. (2005) "Evaluación de las experiencias participativas en la gestión local de Cataluña: potencialidades y amenazas" Gestión y Análisis de Políticas Públicas 32: 79-98.

Cuesta, M.; Font, J.; Ganuza, E.; Gómez, B.y Pasadas, S. (2008) Encuesta deliberativa, Madrid, CIS.

Del Pino, E. y Colina, C. (2003) Las nuevas formas de participación en los gobiernos locales, Madrid, Fundación Alternativas.

Díaz, L. (2012) Polítiques publiques dels Municipis Catalans. Barcelona, Fundació carles Pi i Sunyer.

Direcció General de Participació Ciutadana (2010) Procés participatiu sobre la Muntanya de Sant Miquel (Opúsculo informativo), Barcelona, Generalitat de Catalunya y Ajuntament de Setcases.

Dryzek, J. (2002) Deliberative democracy and beyond: liberals, critics, contestations, Oxford, Oxford University Press. 
Fishkin, J. (1991) Democracy and deliberation: new directions for democratic reform, New Haven, Yale University.

Fishkin, J. (1995) The voice of the people: public opinion and democracy, New Haven, Yale University.

Fishkin, J. (2009) When the people speak: deliberative democracy and public consultation, Oxford, Oxford University Press.

Fishkin, J. y Laslett, P. (2003) Debating deliberative democracy, Malden, Blackwell.

Font, J. (2001): Ciudadanos y decisiones públicas, Barcelona, Ariel.

Font, J. y Blanco, I. (2006) Polis, la ciudad participativa, Barcelona, Diputació de Barcelona.

Font, J. y Galais, C. (2009) Experiencies de democràcia participativa local a Catalunya: un mapa analític, Barcelona, Direcció General de Participació Ciutadana.

Fox, C. y Miller, H. (1995) Postmodern Public Administration. Towards Discourse, Londres, Sage.

Fung, A. (2006) "Varieties of participation in complex governance" Public Administration Review 66: 66-75.

Fung, A. (2003) "Survey Article: Recipes for Public Spheres: Eight institutional design choices and their consequences" The Journal of Political Philosophy 11(3): 338-367.

Gutmann, A. y Thompson, D. (1996) Democracy and disagreement, Cambridge, Belknap Press.

Gutmann, A. y Thompson, D. (2004) Why deliberative democracy?, Princeton, Princeton University Press.

Haus, M.; Heinelt, H. y Stewart, M. (2005) “Introduction”, en M. Haus, H. Heinelt y M. Stewart, eds., Urban governance and democracy: Leadership and community involvement, Londres, Routledge.

Held, D. (1995) Democracy and the Global Order, Cambridge, Polity Press.

Hendriks, C. (2006) "When the Forum Meets Interest Politics: Strategic Uses of Public Deliberation” Politics \& Society 34(4): 571-602.

Hendriks, C.; Dryzek, J. y Hunold, C. (2007) "Turning Up the Heat: Partisanship in Deliberative Innovation”, Political Studies 55: 362-383.

Jorba, L. (2008) Democràcia deliberativa: la transformació de preferències en el procés deliberatiu. Tesi doctoral, Departament de Ciència Política i Dret Públic, Universitat Autònoma de Barcelona.

Jorba, L.; Martí, J. y Parés, M. (2007) La qualitat en la participació: orientacions per a l'avaluació participada, Barcelona, Fundació Bofill.

Jorba, L. y Anduiza, E. (2009) "Por qué y cómo evaluar la participación”, en M. Parés, coord., Participación y calidad democrática. Evaluando las nuevas formas de democracia participativa, Barcelona, Editorial Ariel.

Mansbridge, J.; Boham, J.; Chambers, S.; Estlund, D.; Follesdal, A.; Fung, A.; Lafont, C.; Manin, B. y Martí, J.L. (2010) "The place of self-interest and the role of power in deliberative democracy" The Journal of Political Philosophy 18 (1): 64-100. 
Papadopoulus, Y. y Warin, P. (2007) “Are Innovative, Participatory and Deliberative Procedures in Policy Making Democratic and Effective?” European Journal of Political Research 46: 445-472.

Parés, M. (2009) Participación y calidad democrática. Evaluando las nuevas formas de democracia participativa, Barcelona, Editorial Ariel.

Parés, M. y Castellà, C. (2009) "Una propuesta de criterios de calidad democrática para evaluar los procesos participativos”, en M. Parés, coord., Participación y calidad democrática. Evaluando las nuevas formas de democracia participativa, Barcelona, Editorial Ariel.

Parés, M. y Resende, P. (2009) "Tipos de prácticas y experiencias de participación promovidas por la Administración Pública: sus límites y radicalidades”, en M. Parés, coord., Participación y calidad democrática. Evaluando las nuevas formas de democracia participativa, Barcelona, Editorial Ariel.

Ruano de la Fuente, J.M. (2010) "Contra la participación: discurso y realidad de las experiencias de participación ciudadana” Política y Sociedad 47 (3): 93-108.

Schkade, C.; Sunstein, C y Hastie, R. (2006) "What Happened on Deliberation Day?”, Chicago John M. Olin Law \& Economics Research Series Working Paper $\mathrm{n}^{\circ}$ 298, The University of Chicago.

Subirats, J. (2011) Otra sociedad ¿Otra política?, Barcelona, Icària.

Subirats, J. (2003) Elementos de nueva política, Barcelona, Centro de Cultura Contemporánea de Barcelona.

Subirats, J.; Blanco, I. y Brugué, Q. (2001) Experiències de participació ciutadana en els municipis catalans, Barcelona, Escola d'Administració Pública de la Generalitat de Catalunya.

Subirats, J. y Parés, M. (2014) "Cambios sociales y estructuras de poder ¿'Nuevas ciudades, nueva ciudadanía?” Interdisciplina 2 (2): 97-118.

Sunstein, C. y Hastie, R. (2008) "Four Failures of Deliberating Groups”. Public Law and Legal Theory Working Paper $\mathrm{n}^{\circ} 215$, The University of Chicago.

Tamayo, M. (2004) "Estrategias de evaluación de políticas públicas”. Documento de estudio para la Comisión para el Estudio y Creación de la Agencia Estatal de Evaluación de la Calidad de los Servicios Públicos y de las Políticas Públicas. Inédito.

Wagenaar, H. (2007) "Governance, complexity and democratic participation: how citizens and public officials harness the complexities of neighbourhood decline" The American Review of Public Administration 37: 17-50. 